\title{
Reconstrução digital para documentação do patrimônio: o caso do edifício Vilanova Artigas
}

Digital reconstruction for the documentation of the heritage: the case of Vilanova Artigas Building

https://doi.org/10.1590/1982-02672020v28e19

\author{
FÁBIO GALLO JÚNIOR' \\ https://orcid.org/0000-0003-2466-260X \\ Universidade de São Paulo / São Paulo, SP, Brasil
}

\section{RODRIGO ANGELO CAMPAGNER VERGILLI²}

https://orcid.org/0000-000 1-9561-781X

Universidade de São Paulo / São Paulo, SP, Brasil

\section{CLAUDIA TEREZINHA DE ANDRADE OLIVEIRA ${ }^{3}$}

https://orcid.org/0000-0002-8628-3130

Universidade de São Paulo / São Paulo, SP, Brasil

RESUMO: O objetivo deste artigo é apresentar e discutir a abordagem adotada para a elaboração de modelos digitais (construtivo e estrutural) do edifício Vilanova Artigas, enfocando acepções, usos e limitações de vários modelos e dos métodos de levantamento de dados. A reconstrução digital do edifício e de suas partes foi feita com base em levantamento topográfico convencional com estação total, varredura a laser associada à fotogrametria, levantamento métrico por meio de instrumentos manuais e análise visual associada ao registro fotográfico. $\bigcirc$ processo de modelagem, por meio

\begin{abstract}
1. Graduado em Arquitetura e Urbanismo com dupla formação em Engenharia Civil, ambas pela Universidade de São Paulo (USP). Mestre em Arquitetura e Urbanismo pela Faculdade de Arquitetura e Urbanismo da Universidade de São Paulo (FAU-USP), instituição em que atualmente cursa doutorado. Docente dos cursos de Graduação em Arquitetura e Urbanismo da Escola da Cidade, do Instituto Federal de São Paulo, da Universidade São Judas Tadeu e do Centro Universitário Fiam-Faam. Pesquisador do projeto Plano de Gestão da Conservação para o Edifício Vilanova Artigas contemplado pelo programa Keeping it Modern, promovido pela Getty Foundation. E-mail: <fgallojr@gmail.com>

2. Mestrando na área de Tecnologia da Arquitetura pela FAU-USP. Possui graduação pela mesma instituição. E-mail: <rodrigovergili@ gmail.com $>$

3. Graduada em Engenharia Civil pela Escola de Engenharia de Lins, mestra e doutora em Engenharia de Construção Civil e Urbana
\end{abstract}


pela Escola Politécnica da USP. Professora associada da FAU-USP e orientadora de doutorado do Programa de Pós-Graduação da mesma instituição. Foi coordenadora do eixo de investigação sobre o concreto aparente do projeto intitulado "Plano de Conservação Preventiva para o Edifício Vilanova Artigas (FAU-USP)", Keeping it Modern Program - The Getty Foundation (2015 - 2017). E-mail: <ctao@usp.br> da integração de vários métodos, permitiu unificar dados históricos, de análises laboratoriais e de ensaios in loco, possibilitando a classificação e o registro de informações de utilidade para o futuro plano de gestão da conservação desse patrimônio. A concepção de um modelo único mostrou-se inviável. A especialidade requer dados específicos para suas análises, que podem recorrer inclusive a diferentes delimitações geométricas (modelagens) das partes constituintes do edifício. Propõe-se como ponto de partida a concepção de modelo simplificado com o objetivo de delimitar genericamente a geometria da edificação e, em seguida, cada especialidade se valeria dessas informações preliminares para concepção do modelo que melhor atenda aos seus objetivos.

PALAVRAS-CHAVE: BIM. Arquitetura Moderna. Edifício Vilanova Artigas. Patrimônio. Modelo de Informação da Construção.

ABSTRACT: The aim of this paper is to present and discuss the approach adopted for the elaboration of digital models of the Vilanova Artigas building, focusing on the meaning, uses and limitations of several models and survey methods as well. The digital reconstruction of the building, and its parts, was carried out based on conventional topographic survey with total station, 3D laser scan associated with photogrammetry, metric survey using manual instruments and visual analysis associated with photographic record. The modeling process, through the integration of several methods, allowed the gathering of historical data, laboratory analyses and on-site tests, enabling classification and registration of useful information for the future conservation management plan of the building. The conception of a single model proved to be infeasible; specialty requires specific data which may even use different geometric delimitations (modeling) of the constituent parts of the building. It is proposed a simplified model with the objective of generally delimiting the geometry of the building and then each specialty would use this preliminary information to design the model that best meets its objectives.

KEYWORDS: BIM. Modern architecture. Vilanova Artigas Building. Heritage. Building information modeling. 
O estudo que fundamenta este artigo foi realizado no âmbito de uma pesquisa intitulada "Subsídios para um Plano da Gestão da Conservação - Edifício Vilanova Artigas", desenvolvida por pesquisadores da FAU-USP lequipe ConservaFAU, sob coordenação geral da Prof. Dra. Maria Lúcia Bressan Pinheiro), apoiada pelo Programa Keeping it Moderm da Fundação Getty (The Getty Foundation). Nessa pesquisa, o plano de trabalho desenvolveu-se segundo três eixos: levantamento e organização da documentação histórica disponível; monitoração do sistema de impermeabilização recentemente aplicado na cobertura; e investigação do concreto armado aparente constituinte das fachadas do edifício. Os trabalhos nos três eixos foram coordenados, respectivamente, pelos professores Beatriz Mugayar Kühl, Antonio Carlos Barossi e Claudia T. de Andrade Oliveira.

Embora os trabalhos tenham sido concluídos em dezembro de 2017, novos eixos de pesquisa acadêmica foram estruturados, dando continuidade, entre outros temas, à reconstrução digital do edifício.

O edifício Vilanova Artigas foi projetado na década de 1960, entre 1961 e 1966, pelos engenheiros-arquitetos João Batista Vilanova Artigas e Carlos Calscaldi para abrigar a nova sede da Faculdade de Arquitetura e Urbanismo da Universidade de São Paulo. Concebido em concreto armado aparente e com área construída de $21.250 \mathrm{~m}^{2}$, o prédio da FAU, como também é conhecido, teve sua estrutura calculada pelo escritório do engenheiro José Carlos de Figueiredo Ferraz.

Construído entre 1967 e 1969, é considerado um exemplar significativo da arquitetura moderna paulista, sendo tombado pelo Conselho de Defesa do Patrimônio Histórico, Arqueológico, Artístico e Turístico do Estado de São Paulo (Condephaat), órgão de preservação estadual, em 1981, e pelo Conselho Municipal de Preservação do Patrimônio de São Paulo (Conpresp), órgão de preservação municipal, em 1991.

$\bigcirc$ aprofundamento cognitivo da obra, a partir da pesquisa histórica e de levantamentos de campo, propiciou a elaboração de um detalhado cadastro do edifício, até então inexistente.

Do ponto de vista metodológico, a elaboração do cadastro deve preceder qualquer intervenção no patrimônio arquitetônico. $\bigcirc$ processo de elaboração do cadastro, como esclarece Oliveira, ${ }^{4}$ não é apenas o "[...] levantamento rigoroso da geometria do edifício na condição em que foi encontrado [...]", mas faz parte de uma etapa cognitiva de sucessivas aproximações da edificação buscando a compreensão da sua história. 
[...] cadastros permitem leitura mais detalhada da evolução do organismo arquitetônico e suas transformações, além de ensejarem a avaliação das deformações estáticas que a estrutura do edifício vem sofrendo, para que se possam aplicar as soluções corretivas. Mostram, inclusive, certas irregularidades construtivas que facilitam o entendimento da história do edifício $[\ldots]^{5}$

A partir do entendimento de que o cadastro é, de fato, um processo de (re) conhecimento da obra, no âmbito da citada pesquisa foi desenvolvida uma consistente campanha de levantamentos de campo llevantamento topográfico convencional com estação total, varredura a laser associada à fotogrametria, levantamento métrico por meio de instrumentos manuais e análise visual associada ao registro fotográfico) que culminaram na reconstrução digital da estrutura do edifício, por meio da elaboração de modelos com várias funcionalidades. Especial atenção foi dada à cobertura e às empenas de concreto armado, dois sistemas que compõem a envoltória do edifício e são de interesse prioritário na primeira etapa do seu plano de conservação.

Nas superfícies de concreto aparente das empenas, a proteção é dependente das propriedades do concreto, especialmente da sua porosidade e das lacunas e descontinuidades superficiais características dos processos de moldagem com fôrmas de madeira no seu estado bruto, bem como da pequena espessura de cobrimento das armaduras derivada das limitações de moldagem à época da construção. Apesar de serem a expressão de significativos avanços tecnológicos do cálculo estrutural, grandes edifícios da arquitetura moderna com estruturas esbeltas de concreto armado aparente, paradoxalmente, são ameaçados por alguns dos atributos que o definem como patrimônio cultural. A porosidade, as lacunas e descontinuidades são as mesmas que tornam essas superfícies vulneráveis aos mecanismos de deterioração, principalmente à corrosão das armaduras induzida pela carbonatação, o que pode descaracterizála permanentemente, além de comprometer a segurança da própria estrutura. Portanto, a escolha das empenas como um dos sistemas a ser modelado com vistas à conservação do edifício justifica-se em razão dos seus valores patrimoniais - estético, histórico, técnico - e também pelo fato de fazerem parte do sistema estrutural do edifício, constituindo um dos conjuntos de elementos mais vulneráveis aos impactos das manifestações patológicas predominantes.

Quanto à cobertura do edifício - projetada em laje de concreto armado com armadura passiva, com vãos livres arrojados para a época e originalmente impermeabilizada com membrana elastomérica aderida -, a escolha para modelagem se deu em razão do nível crítico de degradação do concreto e das armaduras, resultado de uma combinação de falta de manutenção, inadequação do sistema de drenagem de águas pluviais e da deformação lenta (fluência) a que 
toda a estrutura está sujeita durante sua vida útil. A modelagem da cobertura também se constitui, simultaneamente, em desafio técnico e oportunidade de documentação de uma estrutura peculiar, composta por vigas de seção não convencional e lajes que conformam um sistema único de grelha estrutural.

Dada à extensão do edifício, inicialmente alguns modelos foram elaborados a partir de informações contidas no projeto de fôrmas, posteriormente atualizados com os resultados dos levantamentos de campo.

aprofundamento cognitivo abrangeu também a investigação dos materiais e do estado de conservação da cobertura e das empenas, resultados que também estão sendo incorporados aos modelos, compondo uma base de dados necessários às futuras etapas de manutenção preventiva e corretiva do edifício.

Com base no exposto, o objetivo deste artigo é apresentar a abordagem adotada para a elaboração de modelos digitais (construtivo e estrutural) do edifício Vilanova Artigas, enfocando acepções, usos e limitações dos vários modelos.

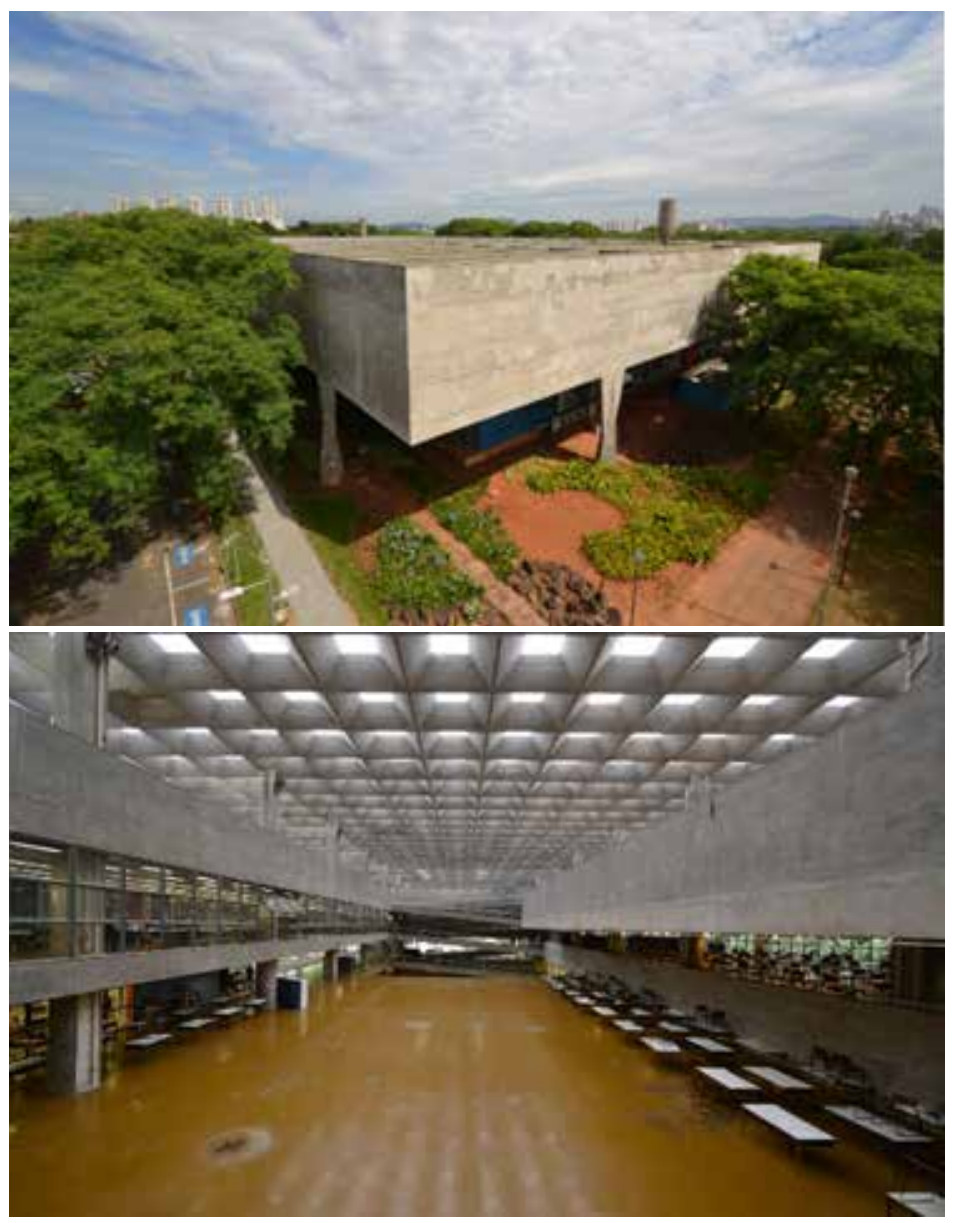

Figura 1 - Edifício Vilanova Artigas: acima, perspectiva das empenas lempena sudeste no primeiro plano); abaixo, perspectiva interna do salão Caramelo e cobertura do edifício. Fotos: Equipe ConservafAU, 2016 e 2015, respectivamente. 


\section{UM MODELO ÚNICO PARA O EDIFÍCIO E SUAS ACEPÇÕES}

Devido à singularidade da estrutura de concreto armado aparente do edifício Vilanova Artigas, seu modelo digital foi elaborado a partir de informações geométricas constantes no projeto de fôrmas, desenvolvido pelo Escritório Técnico Figueiredo Ferraz na década de 1960. O modelo, elaborado na versão estudantil do software Autodesk Revit $2015^{\circledR}$, requereu desenvolvimento de famílias específicas para atender aos formatos não convencionais dos elementos estruturais que o constituem, bem como às variações das seções transversais ao longo de seus comprimentos. A Figura 2 traz exemplos de famílias paramétricas desenvolvidas para os pilares do edifício

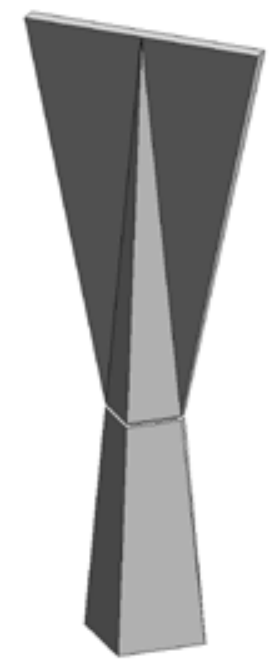

FAMILIA DE PILARES EXTERNOS

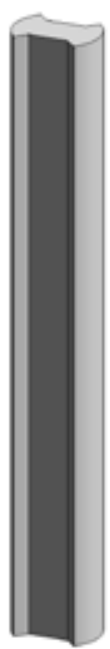

FAMILLA DE PILARES INTERNOS

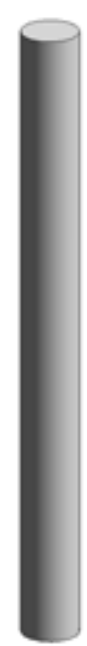

FAMILIA DE PILARES INTERMEDIARIOS

Figura 2 - Famílias paramétricas desenvolvidas para os pilares do edifício Vilanova Artigas. Fonte: autores

Inicialmente, concebeu-se o modelo digital com a pretensão de produzir uma base única e oficial do edifício. A premissa foi a de que esse modelo pudesse ser empregado para armazenar a expressiva quantidade de dados gerados pelas pesquisas bibliográficas, documentais, de campo e laboratoriais. Assim, o modelo poderia ser utilizado em estudos de diversos campos - análise estrutural, simulação de conforto ambiental, funcionalidade das instalações, gestão da manutenção, estudos de durabilidade, entre outras - cujos resultados produzidos pudessem ser armazenados num único banco de dados a ele associado. 
No entanto, demandas reais procedentes de análises para caracterização do concreto do edifício, em curso na época da modelagem, revelaram contradições e as limitações de um modelo único previsto inicialmente, que serão discutidas a seguir.

\section{ACEPÇÃO DO MODELO DIGITAL FRENTE AO PROGRAMA DE ENSAIOS DESTRUTIVOS}

Tendo em vista que não foram identificados registros históricos confiáveis com o detalhamento dos materiais usados na estrutura (traço ou traços do concreto, resistência de cálculo, tipo de cimento e de agregados utilizados) e dos procedimentos adotados em obra, um programa de ensaios foi planejado com o objetivo de extrair testemunhos para a caracterização do concreto e investigar as armaduras quanto ao risco de corrosão. Cabe destacar que um projeto contendo o detalhamento dos trabalhos - incluindo a retirada de material, tipos de ensaios e recomposição das superfícies do concreto - foi submetido à aprovação dos órgãos oficiais /Conpresp e Condephaat) em 2016. As análises laboratoriais referidas foram realizadas por pesquisadores especializados do Instituto de Pesquisas Tecnológicas do Estado de São Paulo (IPT), e os resultados e análises finais estão acessíveis no relatório final do projeto. ${ }^{6}$

Os testemunhos de concreto foram utilizados para caracterização do material com o objetivo de determinar suas características físicas e químicas, bem como sua composição, relação água/cimento e natureza dos agregados que o constituem. A caracterização foi feita por meio dos ensaios de petrografia, porosimetria por intrusão de mercúrio, reconstituição do traço, termogravimetria, difratometria de raios $X$, microscopia eletrônica de varredura, além da determinação da profundidade de carbonatação, da resistência à compressão axial, do módulo estático de deformação à compressão, da massa específica, volume de vazios e absorção de água.

Nos locais delimitados para a escarificação da argamassa de reparo e acesso das armaduras, foram realizados ensaios de determinação da umidade superficial e profunda (até $20 \mathrm{~cm}$ de profundidade) do concreto, frente de carbonatação, exame visual do aspecto das armaduras quanto à presença de produtos de corrosão, resistividade do concreto, cobrimento das armaduras, potencial e taxa de corrosão das armaduras.

Com os resultados obtidos nessas análises, caracterizaram-se as condições atuais do concreto existente nas fachadas do edifício e o nível de proteção oferecido às barras de aço das armaduras e a sua vulnerabilidade à corrosão. 
7. Cf. Associação Brasileira de... (2015).
O conhecimento das características desse concreto e da condição das armaduras é necessário para especificação da argamassa de reparo que se empregaria em áreas danificadas das fachadas, bem como para a especificação das futuras ações de manutenção do concreto aparente.

Como já detalhado, as análises laboratoriais requeriam a extração de testemunhos de concreto das empenas do edifício. Para determinação da quantidade de testemunhos a serem extraídos, foram necessários estudos que visavam à garantia da representatividade amostral, os quais pressupunham, de acordo com a normalização vigente - NBR 7680-1,7 definição dos volumes de concreto das empenas, como uma das variáveis envolvidas, para a determinação dos possíveis lotes de concretagem. Porém, os volumes de concreto necessários ao estudo não se referiam à empena como um todo. Necessitava-se da determinação de volumes parciais referentes às faixas de concretagem da empena, delimitadas pelas juntas de concretagem visíveis em suas superfícies, conforme resumido na Figura 3.

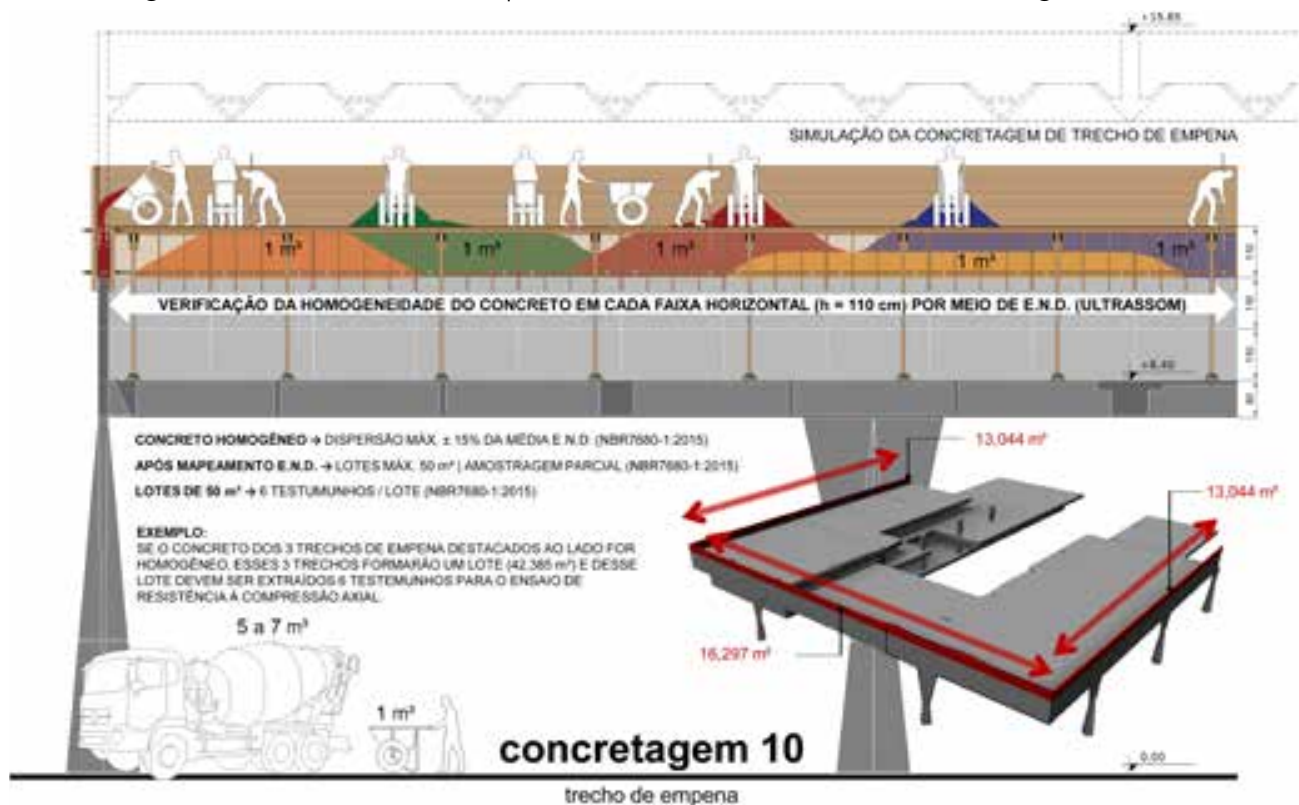

Figura 3 - Simulação da concretagem de um dos trechos da empena do edifício, ilustrando os distintos lotes de concretagem, segundo os quais, sob essa abordagem, as empenas devem ser modeladas. Fonte: autores

Por um lado, para essa demanda requeria-se que a empena de concreto fosse modelada digitalmente segundo geometria representativa das etapas de construção (para que se tornasse possível a obtenção dos volumes concretados). Por outro lado, do ponto de vista da análise estrutural, esse objeto deveria ser modelado continuamente. Isso posto, torna-se evidente que um único modelo digital não satisfaria ambas as necessidades, ficando o impasse: a empena de concreto 
deve ser modelada segundo o viés construtivo ou estrutural? A Figura 4 ilustra um recorte dos dois modelos concebidos.
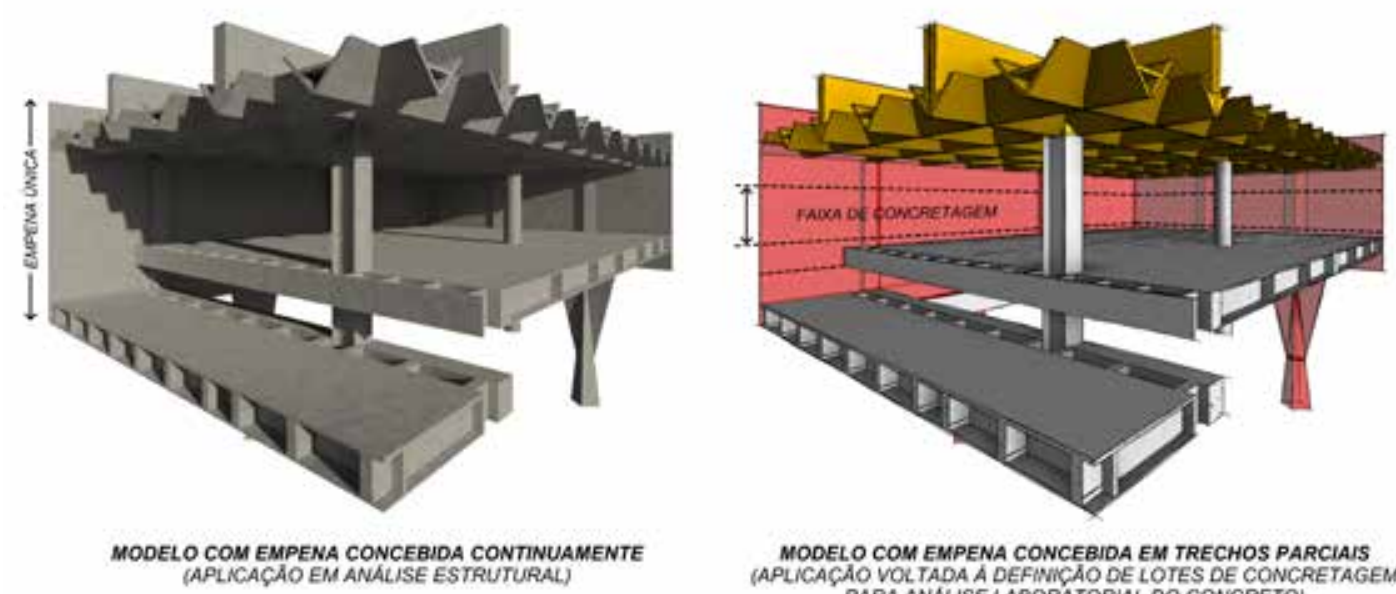
AAPLICA GAO VOL TADA A DEFINICAO DE LOTES OE CONCRETAGEM PARA ANALISE LABORATORIAL DO CONCRETO)

Figura 4 - Modelos digitais em que a empena de concreto armado foi concebida continuamente como objeto único (à esquerda) e como objetos parciais ao longo da altura (à direita). Fonte: autores

A mesma questão estende-se à modelagem das lajes nervuradas dos pisos e vigas da cobertura do edifício, cujas etapas de concretagem delimitam sólidos distintos daqueles que os representam estruturalmente.

Uma vez determinada a região de extração de testemunhos de concreto e suas quantidades, necessitava-se posicionar esses furos nas empenas. posicionamento dos furos deveria considerar, no entanto, dentro da região de extração, áreas com baixa taxa de armadura, para minimizar eventuais danos à armadura durante a operação de extração. Portanto, requisitava-se para essa demanda a locação das armaduras das empenas e uma nova tomada de decisão: deveriam essas armaduras ser modeladas? Como se dispunha do projeto de armações da estrutura de concreto armado do edifício, caso a resposta fosse afirmativa, essas armaduras poderiam também ser compartilhadas com o modelo digital para análise estrutural do edifício, em fase de incubação naquele momento. No entanto, como o tempo requerido para modelagem das armaduras era incompatível com o disponível para definição das áreas de extração, optouse por apenas delimitar no modelo digital regiões na superfície das fachadas do edifício, com menores taxas de armadura, conforme ilustrado na Figura 6 . Essas marcações na empena foram desenvolvidas por meio de ferramentas de "região preenchida" da aba "anotações" no Autodesk Revit $2015^{\circledR}$. 
Figura 5 - Detalhe da empena com a impressão do desenho das tábuas de pinho usadas como fôrma do concreto. Os veios da madeira, bem como a largura nominal das tábuas $(30 \mathrm{~cm})$ são visíveis em toda a extensão das empenas. Fonte: autores

Figura 6 - Indicação de região com baixa taxa de armaduras principais para extração de testemunhos na empena noroeste. Fonte: autores

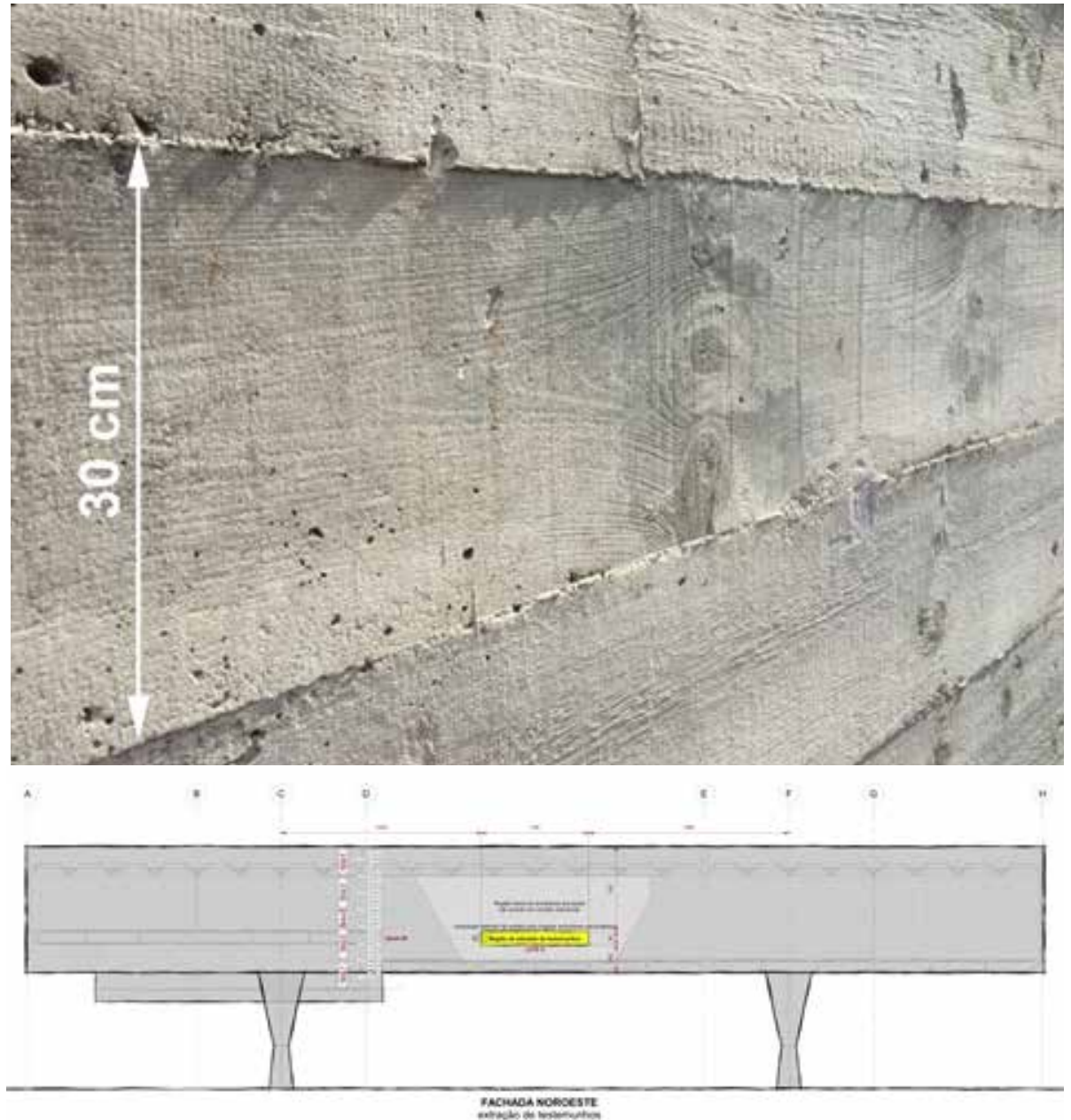

190

100

$\pm 00$

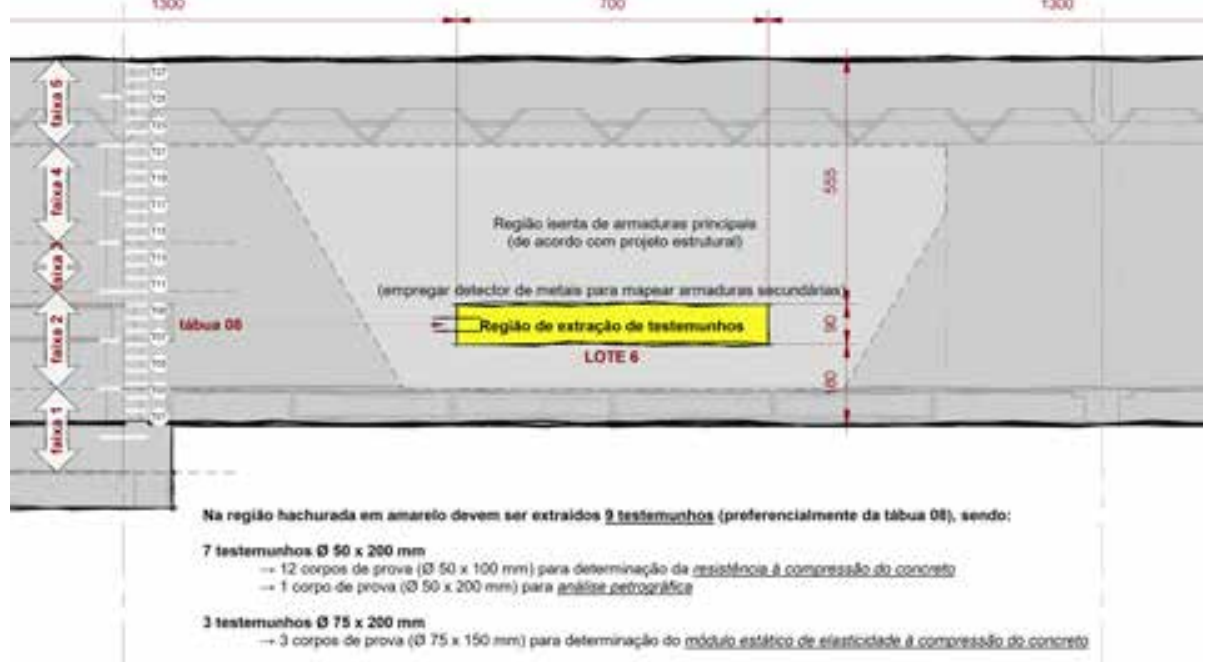


Outro aspecto relevante na indicação da posição das extrações diz respeito ao referencial físico a ser seguido pelo operador em campo para execução do serviço. Nesse sentido, as marcas das tábuas impressas na superfície externa das empenas de concreto representam importante referencial ao longo de sua altura, o que proporcionou nova reflexão sobre a necessidade de sua representação no modelo digital (Figura 5).

Como solução, elaborou-se uma "régua de tábuas" junto à indicação das faixas de concretagem (à esquerda no desenho da Figura 6) para servir de referência à extração em campo.

\section{ACEPÇÃO DO MODELO DIGITAL FRENTE AO PROGRAMA DE ENSAIOS NÃO DESTRUTIVOS}

Outra variável relevante à definição da quantidade de testemunhos a serem extraídos referia-se à homogeneidade do concreto, estimada por meio de ensaios não destrutivos - END - os quais são particularmente relevantes no âmbito de edifícios dotados de valor cultural, pois possibilitam conhecer os materiais que os constituem sem descaracterizá-los.

Dois programas de END foram realizados no edifício: um visando à determinação da velocidade de propagação de onda ultrassônica no concreto (método por ultrassom) - NBR 8802 (ABNT, 2013) - e outro visando à avaliação da dureza superficial do concreto obtida pelo esclerômetro de reflexão (esclerometria) - NBR 7584 (ABNT, 2013). Ambos os programas de ensaios trouxeram desdobramentos similares quanto ao armazenamento e processamento dos dados no modelo digital do edifício. Por trazer complexidade ligeiramente superior frente a esse viés, serão abordadas neste artigo as estratégias empregadas para contemplar no modelo os dados provenientes do método de ensaio por ultrassom com arranjo de transdutores em transmissão indireta, cujos resultados foram publicados em Gallo Jr. ${ }^{8}$

A realização do ensaio pressupunha o estabelecimento de referenciais para posicionamento do gabarito de madeira junto à superfície da empena. Conforme prescrição normativa, como o número de ensaios a realizar seria elevado, tornava-se inviável que os pontos de ensaio fossem posicionados segundo coordenadas cartesianas no plano da empena. Como estratégia para o posicionamento dos ensaios, elegeu-se como referência a paginação das chapas de madeira compensada impressas na superfície interna das empenas de concreto, que lhes serviram de fôrma durante a construção. Para o trabalho de levantamento dessa paginação, imprimiramse em papel as vistas internas das quatro empenas e, com o auxílio de trena e por 
meio de inspeção visual - já que havia bastante regularidade quanto aos formatos e dimensões das chapas de madeira compensada -, desenharam-se as chapas à mão, em campo, sobre as fachadas impressas, conforme ilustrado na Figura 7.

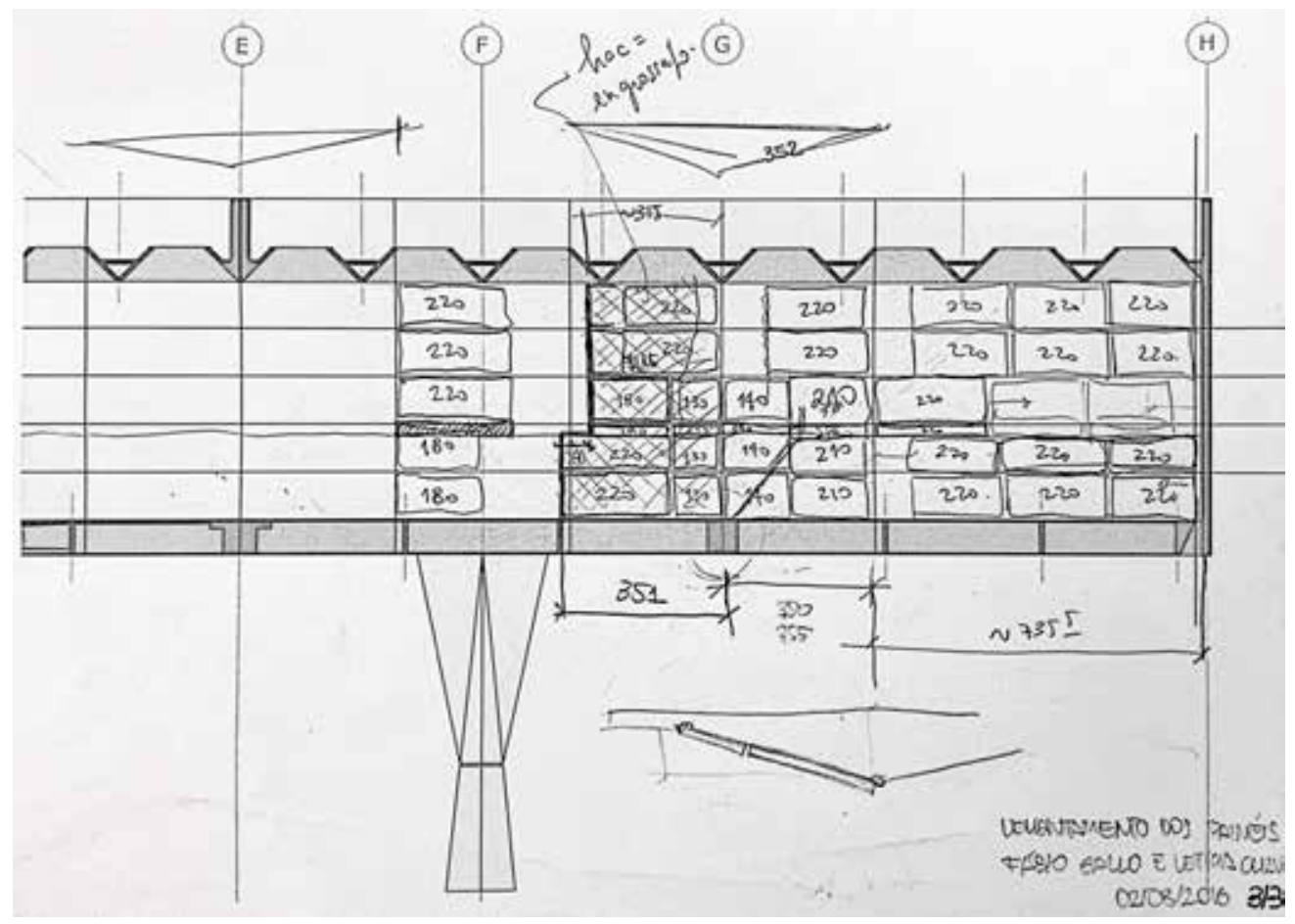

Figura 7 - Levantamento da paginação das chapas de madeira compensada impressas na superfície interna da empena sudeste do edifício Vilanova Artigas que lhe serviram de fôrma para concretagem durante a construção. Fonte: autores

O registro da paginação no modelo digital se fez mediante criação de família de chapas de madeira compensada concebida na categoria de família "Item de detalhe métrico". Com essa família, obtinham-se quaisquer formatos de chapa para inserir na superfície interna da empena. A Figura 8 mostra à direita o desenho da placa de madeira compensada em vista frontal. À esquerda, indicam-se os parâmetros criados para atender à variabilidade geométrica solicitada à família "Fôrmas_molde.rfa".

Portanto, com o emprego dessa família, ao inserir a chapa na face interna da empena, indicam-se automaticamente as quantidades e tipos de ensaios de ultrassom que caberiam na superfície que a delimita. Quanto aos tipos de ensaio - duplos, simples verticais e simples horizontais -, decorrem da posição do gabarito empregado em sua execução, conforme apresentado na Figura 9. 

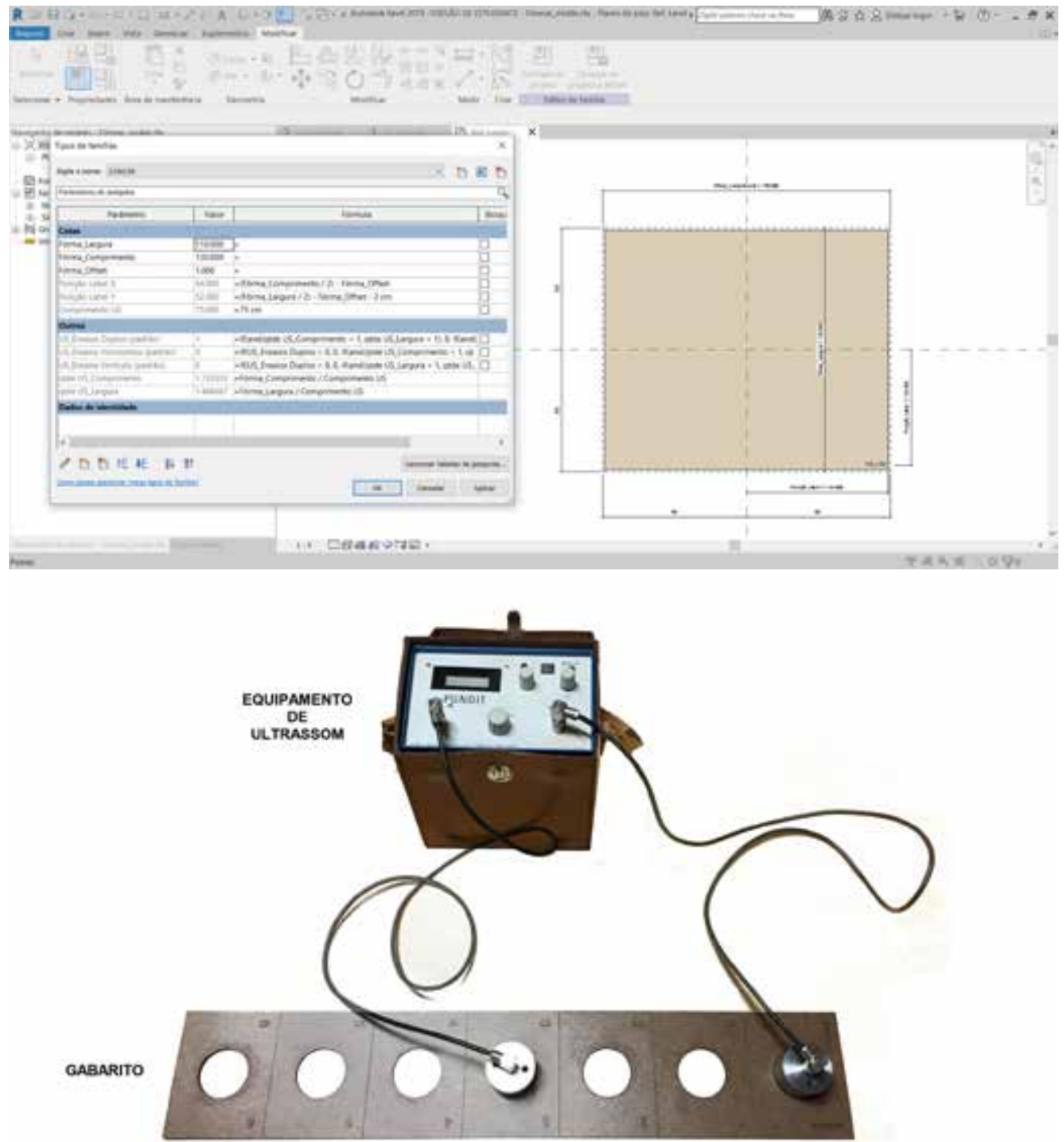

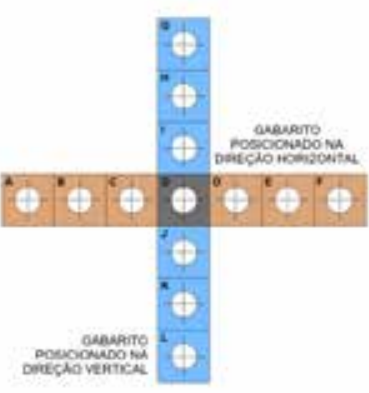

ENSANO DUPLO

GABAFTO POSICIONADO NA VERTICAL E NA HORIZONTAL

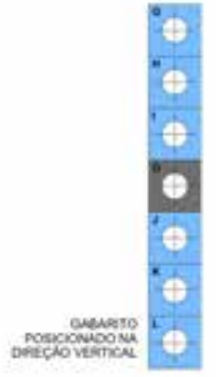

ENSANO SIMPLES VERTICAL GABARITO POSICIONADO NA VERTICAL.

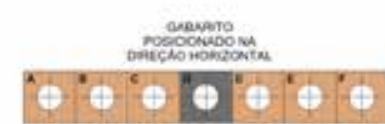

ENSAJO SMPLES HORIZONTAL GABARITO POSICIONADO NA HORZZONTAL
Figura 8 - Famílias paramétricas desenvolvidas para as chapas de madeira compensada impressas na superfície interna das empenas de concreto armado do edifício Vilanova Artigas. Fonte: autores
Figura 9 - Equipamento de ultrassom, gabarito de madeira e tipos de ensaio realizados no edifício Vilanova Artigas. Fonte: autores 
Para a inserção do gabarito no modelo digital, criou-se, a partir da categoria de família de "anotação genérica", a família "ultrassom. .fa", capaz de suportar os três tipos de ensaio apresentados na Figura 9. A Figura 10 apresenta o ensaio duplo desenvolvido nessa família e os parâmetros associados.

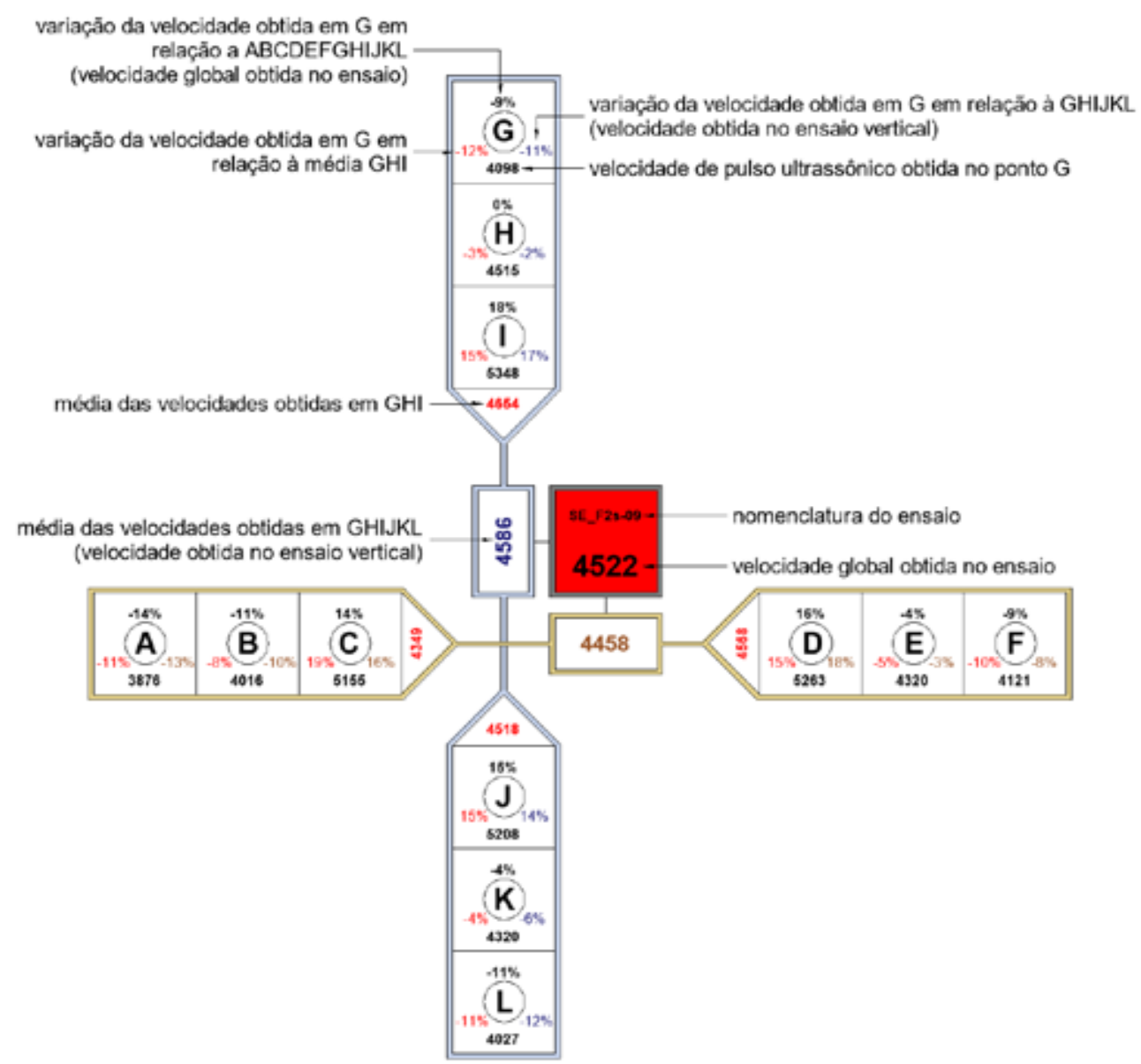

Figura 10 - Parâmetros da família de ensaios de ultrassom: exemplo de ensaio duplo. Fonte: autores

Durante o ensaio, o equipamento informa os tempos de trânsito do pulso ultrassônico entre emissão (origem) e recepção (pontos A, B, ..., K e L). Com o auxilio de um laptop, digitou-se concomitantemente à realização do ensaio cada leitura de tempo no campo previsto da família $\left(t_{A}, t_{B}, \ldots, t_{K}\right.$ e $\left.t_{1}\right)$. Conforme se prosseguia o preenchimento, equações desenvolvidas dentro da família forneciam os resultados de velocidade e suas variações em relação às médias. Com isso, pôde-se identificar valores espúrios lleituras com variação acima de 10\% em 
relação à média) e se reposicionar em tempo real o gabarito para que os transdutores se afastassem de uma região fissurada, de superfícies rugosas, ou ainda da direção principal de armaduras (fatores que influenciam o resultado do ensaio).

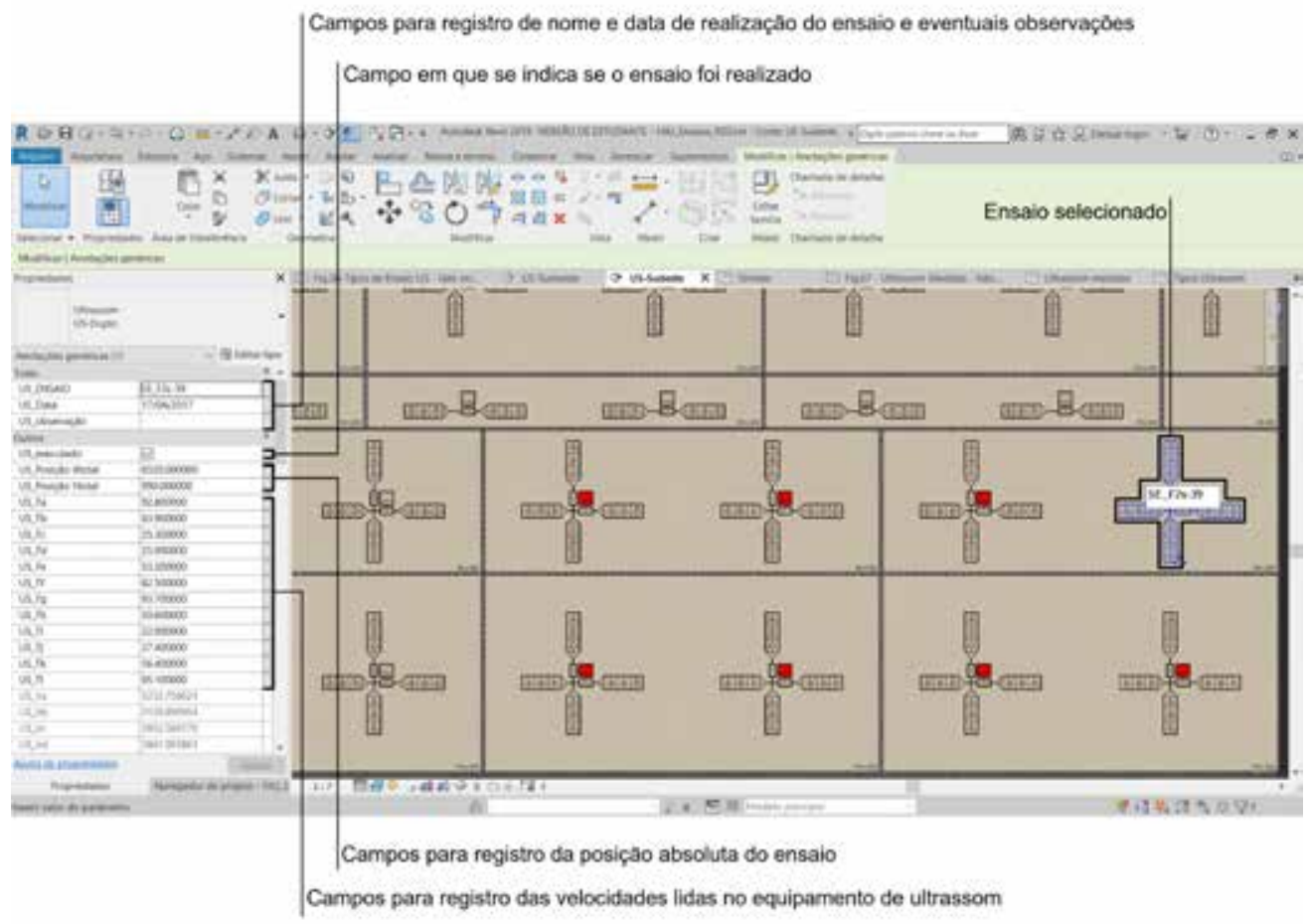

Figura 11 - Trecho da superfície interna da empena sudeste do edifício com os ensaios de ultrassom posicionados a partir do referencial de paginação das chapas de madeira compensada. Fonte: autores

A Figura 11 apresenta no modelo digital trecho da superfície interna da empena sudeste do edifício com os ensaios de ultrassom posicionados a partir do referencial de paginação das chapas de madeira compensada.

Concebeu-se ainda a família vislumbrando a possibilidade de leitura dos resultados em tabelas nas quais se poderia filtrar valores de velocidades de interesse (muito baixas ou muito altas) e identificá-las graficamente sobre a empena. A Figura 12 a seguir ilustra um exemplo de correspondência entre tabela e representação gráfica dos ensaios de ultrassom realizados na empena SE do edifício.

Por fim, ressalta-se que o ensaio de ultrassom foi concebido para ser realizado integralmente - desde o posicionamento, registro dos dados e 


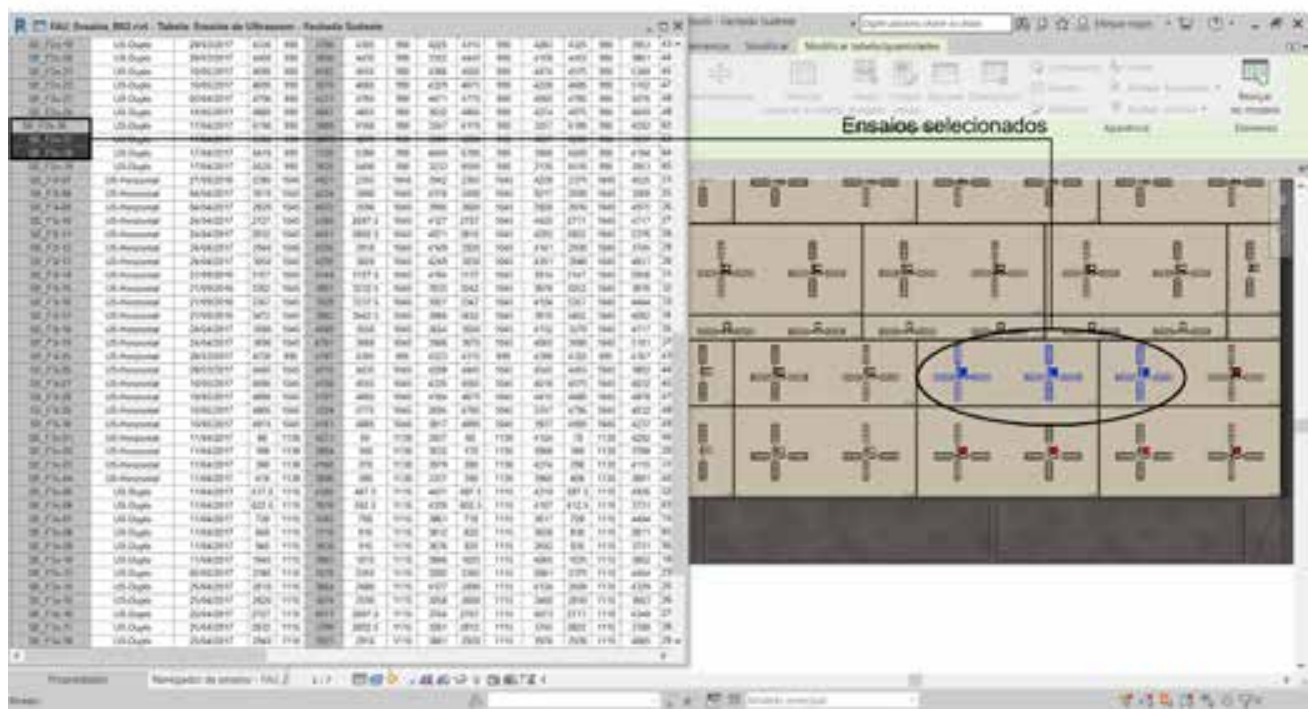

Figura 12 - Correspondência entre tabela e representação gráfica dos ensaios de ultrassom realizados na empena sudeste do edifício Vilanova Artigas. Fonte: autores

processamento dos resultados - com auxílio de ambiente BIM (Autodesk Revit $2015^{\circledR}$ ) concomitantemente a sua execução, sem necessidade de softwares de cálculo como MS Excel ${ }^{\circledR}$, ainda que a possibilidade de exportação da tabela para esse tenha sido perfeitamente viável.

\section{ACEPÇÃO DO MODELO DIGITAL FRENTE AO LEVANTAMENTO GEOMÉTRICO INSTRUMENTAL DO EDIFÍCIO}

Foi realizado um levantamento topográfico cadastral da estrutura do edifício, por meio de uma estação-total, no primeiro semestre de 2016. O resultado consistiu em representações bidimensionais (plantas, cortes e elevações 2D) "as-built" da estrutura georreferenciada. Como atividade complementar, também foi realizado um levantamento das cotas de fundo dos cruzamentos de viga da cobertura com o objetivo de estimar, por meio de comparação com valores de referência de projeto, o deslocamento vertical, iá visível, de alguns pontos da face inferior dessa estrutura. Destaca-se que o comportamento estrutural dessa cobertura sempre foi um desafio para as atividades de manutenção. Projetadas em planos com declividade de 0,5\%, originalmente deveriam permitir o escoamento da água da chuva, por gravidade, para os pontos de captação, localizados próximos aos pilares, como ilustrado na Figura 13. 
Com o tempo, os efeitos causados pelo carregamento de longa duração, relacionados à deformação lenta do concreto, alteraram a configuração original

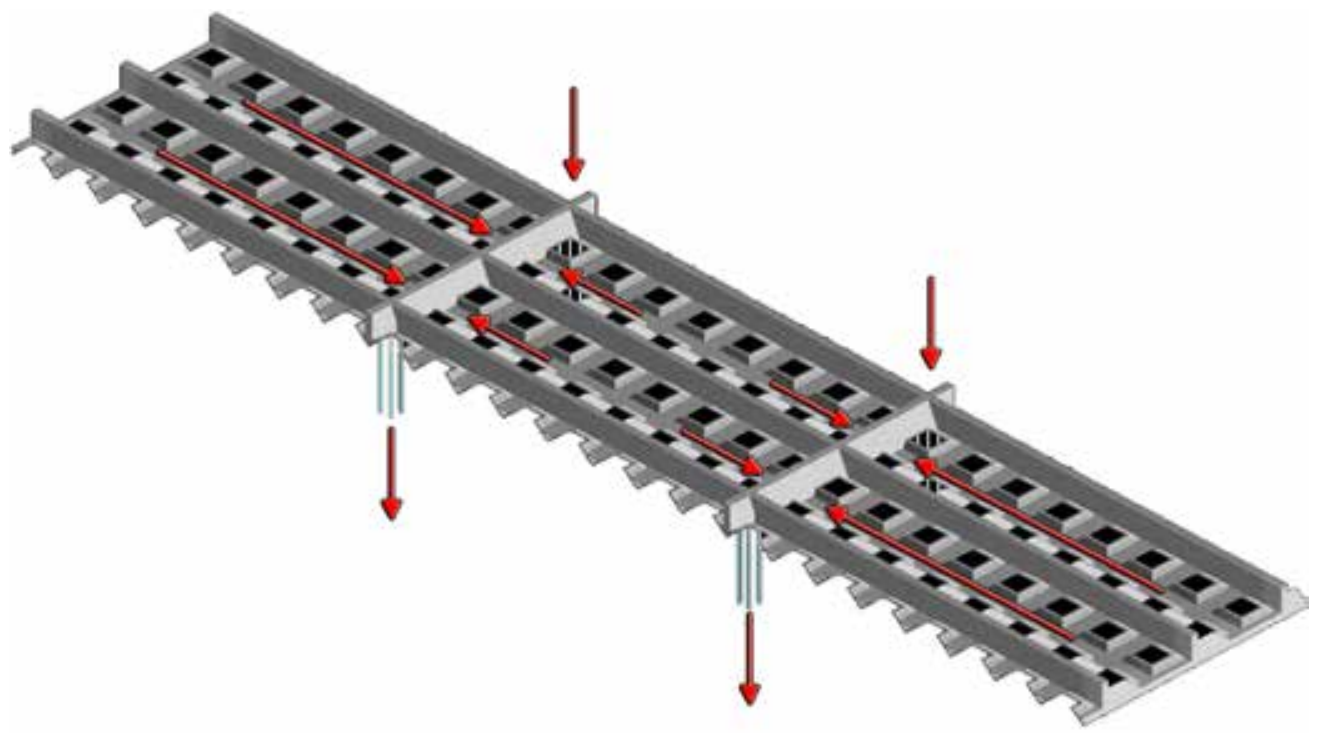

Figura 13 - Modelo do escoamento das águas pluviais na cobertura do edifício, segundo premissas do projeto original. As setas indicam o fluxo da água nas lajes, em direção aos pontos de captação e, verticalmente, nos tubos de queda. Fonte: autores

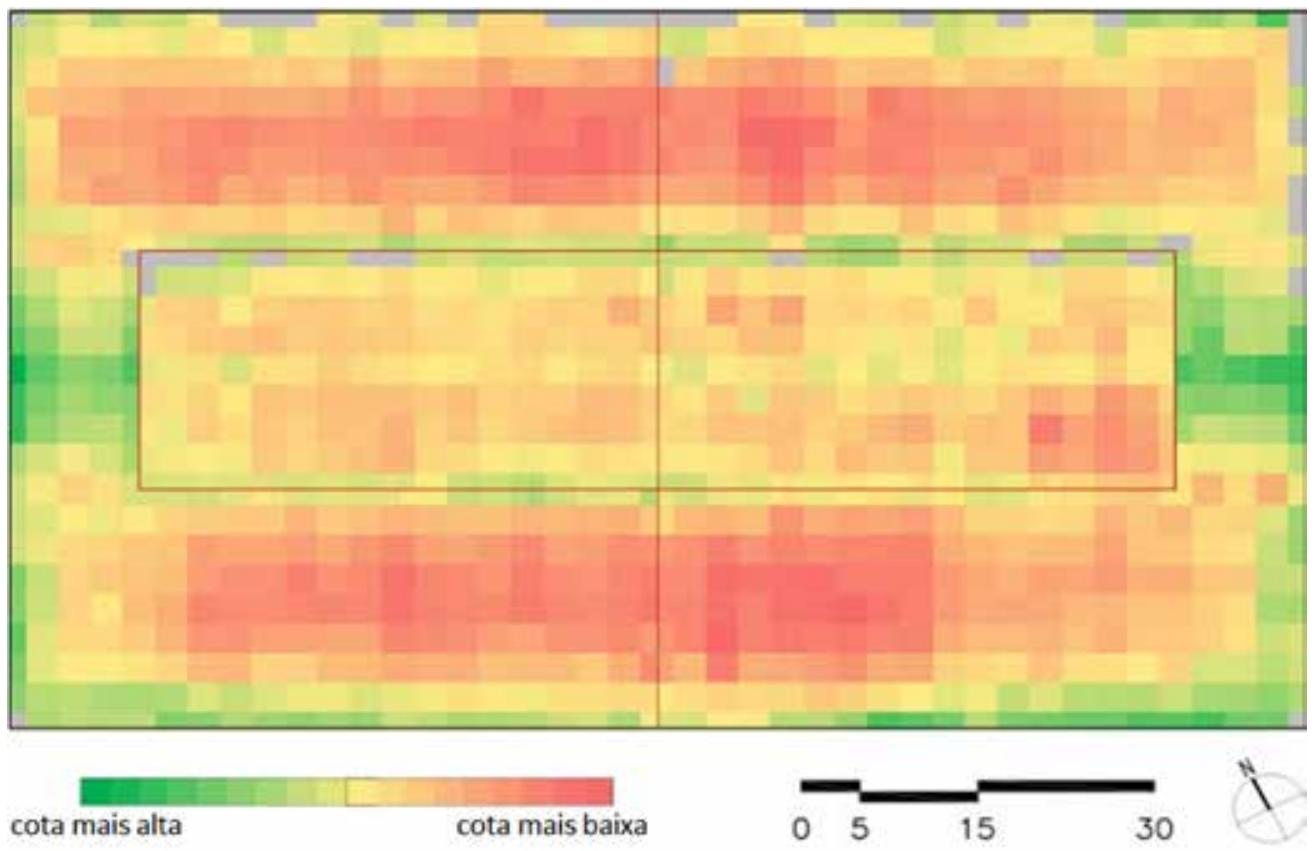

Figura 14 - Planta da cobertura com representação das cotas de fundo das vigas, em escala cromática, obtidas por levantamento topográfico. Fonte: autores 
da laje, dificultando o escoamento das águas pluviais e potencializando o seu acúmulo nas lajes. Segundo declarações de profissionais que participaram direta e indiretamente da construção do edifício, documentadas em Pinheiro, ${ }^{9}$ a deformação da cobertura foi potencializada pela insuficiência das contraflechas, bem como pela sobrecarga resultante da sobreposição de camadas de argamassa com o objetivo de recompor o plano de escoamento das águas pluviais.

O levantamento topográfico proposto registrou as cotas de fundo das vigas, distribuídas numa malha de 2,75 m × 2,75 m (módulo dos domos da cobertura, com forma de tronco de pirâmide de base quadrada). Os valores obtidos foram tratados visando à compensação da declividade prevista para o escoamento das águas pluviais das lajes de cobertura, conforme definida em projeto. $\bigcirc$ resultado qualitativo dessa análise pode ser observado na planta cromática, ilustrada na Figura 14.

Para calibração das cores, definiu-se como "amarelo neutro" o valor médio das cotas de apoio estrutural da cobertura (pilares internos), pressupondo a não ocorrência de deslocamentos verticais especificamente nesses pontos. Tons em verde corresponderiam a trechos da cobertura localizados em cota superior à prevista em projeto, e os tons em vermelho representam os deslocamentos verticais negativos apurados, ou seja, as cotas inferiores às previstas em projeto. $\bigcirc$ cotejamento dessa planta com a atual condição da cobertura comprova que o acúmulo de água coincide com as áreas de cotas mais baixas, ou seja, áreas nas quais houve deslocamentos verticais da ordem de $100 \mathrm{~mm}$. Pode-se concluir que o modelo simplificado de deslocamentos relativos - construído a partir do desenho original e das cotas do fundo da laje obtidas por meio do levantamento topográfico - é funcional e pode ser considerado como representativo do estado atual da estrutura deformada.

Até o momento, o modelo simplificado foi útil para explicar as ocorrências observadas na cobertura quanto ao acúmulo de água pluvial e as limitações do sistema de drenagem. Apesar de ainda não incorporados ao modelo único, os deslocamentos reais, obtidos no levantamento topográfico, serão necessários para o desenvolvimento do modelo estrutural. Uma vez que a compatibilização dos deslocamentos medidos e aqueles simulados no modelo numérico permite a estimativa de parâmetros elásticos do material, o módulo de deformação do concreto, determinado em ensaio laboratorial, será cotejado ao módulo de deformação estimado analiticamente, viabilizando a calibração e a aferição do modelo estrutural. 
10. Está em curso o levantamento tridimensional a laser da laje de cobertura do edifício Vilanova Artigas, realizado também pela equipe técnica do DIAPReM. Em 2019 foi concluída uma primeira fase com o levantamento da quase totalidade da face externa da laje; nas próximas fases será concluído o levantamento da face externa e realizado o da face interna.

11. Cf. Castro (2018).

Após o tratamento da nuvem de pontos, feito pela equipe especializada usando o soffware Cyclone ${ }^{\circledR}$, as elevações das quatro fachadas do edifício puderam ser obtidas por meio da exportação dos dados brutos para o Autodesk AutoCAD ${ }^{\circledR}$. A manipulação desses dados brutos, com o ajuste de parâmetros da nuvem de pontos como, por exemplo, a refletância dos materiais, aumenta a acuidade dos dados e viabiliza a análise de aspectos morfológicos das superfícies. O modelo tridimensional representa apenas a envoltória do edifício (Figura 15, à esquerda), não viabilizando estudos, por exemplo, de seções das empenas. Apenas a volumetria dos 14 pilares externos, em forma de tronco de pirâmide, pode ser gerada a partir da nuvem de pontos.

Importantes informações já foram obtidas a partir da nuvem de pontos como, por exemplo, a quantidade, o perímetro e a área de todos os reparos feitos com argamassa estrutural na superfície externa das empenas, em substituição do concreto deteriorado pela corrosão das armaduras induzida por carbonatação, uma das principais manifestações patológicas no edifício, como já explicitado neste texto (Figura 15, à direita). Vale a pena destacar que a quantificação completa das áreas dos reparos não prescindiu de complementos feitos por meio da observação direta com o auxilio de fotografias. Os desenhos das empenas gerados a partir da nuvem de pontos permitiram a identificação de $71 \%$ a $88 \%$ da área total de reparos. Essa limitação se deu, em parte, pelo efeito do sombreamento de árvores nas empenas que impôs restrições ao levantamento por varredura a laser, apesar dos cuidados de reposicionamento da estação para aumentar a confiabilidade dos dados obtidos. Em regiões onde os atributos cromáticos das argamassas e do concreto não são muito distintos, especialmente a luminosidade de acordo com medições feitas por Castro, ${ }^{11}$ a identificação do contorno dos reparos também é dificultada (Figura 16).

Dada a resolução das medidas obtidas na varredura a laser laproximadamente $4 \mathrm{~mm}$, considerando os parâmetros utilizados no levantamento 
12. Cf. Balzani; Maietti; Kühl (2017).
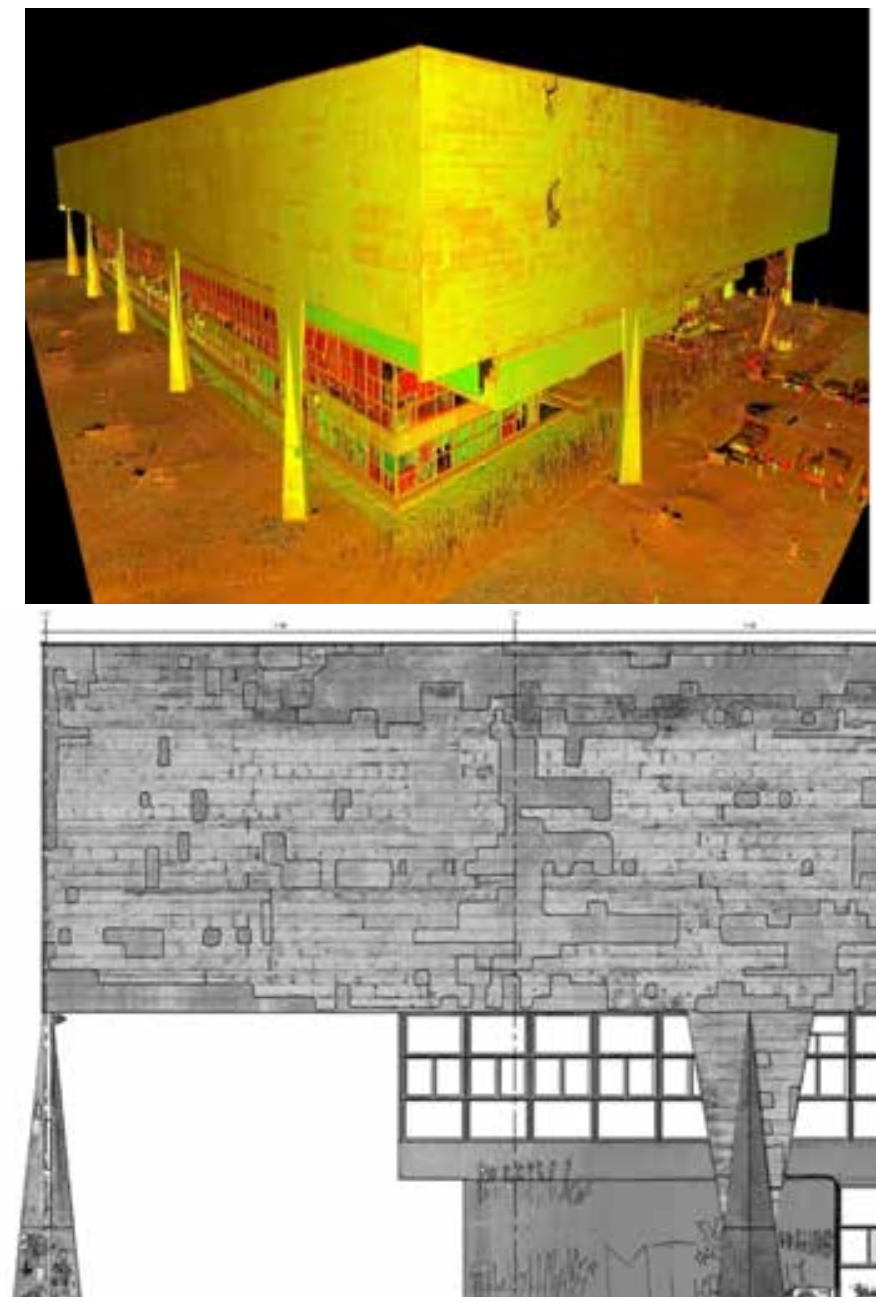

Figura 15 - Modelo tridimensional obtido por varredura a laser (esquerda) das fachadas do edifício. Elevação de parte da fachada sudeste obtida a partir da nuvem de pontos do modelo tridimensional. Fonte: Equipe ConservaFAU, 2016.

realizado) e a escala dos elementos do edifício, outras importantes informações geométricas das empenas, bem como de outros elementos das fachadas visíveis no levantamento, podem ser extraídas desse modelo georreferenciado. Exemplos são as cotas de topo e de fundo das vigas-paredes - elementos estruturais que compõem as empenas -, para a análise de possíveis deslocamentos, localização das juntas de dilatação e dos aparelhos de apoio, paginação das tábuas de pinho da fôrma de concretagem das empenas, entre outros.

Características morfológicas da superfície também podem ser extraídas do modelo. Para tanto, dados como a intensidade do retorno do sinal dos 

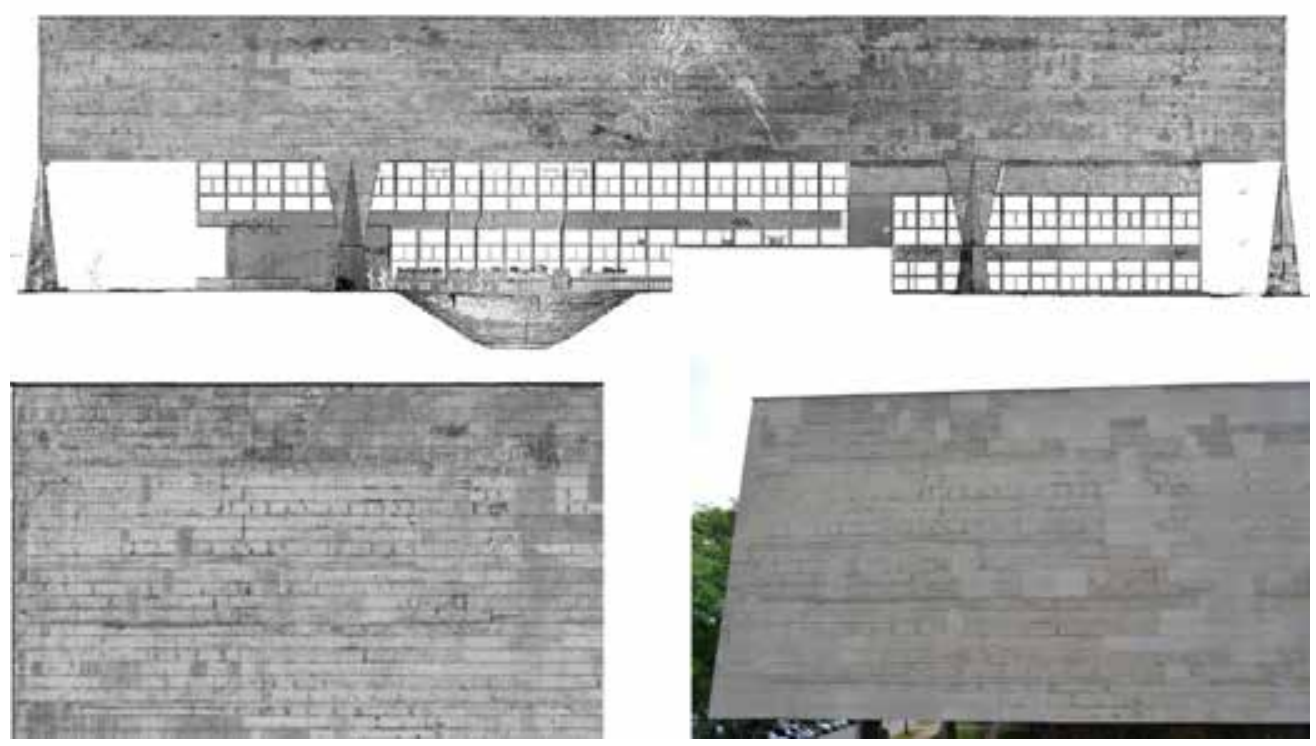

Figura 16 - No alto: elevação completa da fachada sudeste obtida a partir do modelo tridimensional da varredura a laser. O círculo vermelho, em linha pontilhada, indica uma região da empena cujo levantamento foi prejudicado pelo sombreamento das árvores próximas ao edifício. Acima, à esquerda: elevação do trecho da fachada destacada com quadro vermelho. Acima, à direita: fotografia do mesmo trecho da fachada indicado na foto ao lado. Fonte: Equipe ConservaFAU, 2016.

pontos da nuvem são usados para criar a imagem associada às propriedades das superfícies e assim permitir a detecção de defeitos, de biofilme ou de crosta negra, diferença entre materiais de preenchimento de lacunas, entre outras características da superfície do concreto. ${ }^{12}$

No entanto, a identificação e a análise dessas características requerem a manipulação dos já citados parâmetros da nuvem de pontos, além do apoio de outras formas de investigação e conferência in loco.

A nuvem de pontos representa o estado em que se encontravam as empenas no período em que o levantamento foi realizado. Não sendo identificada qualquer ocorrência que tenha alterado significativamente esses elementos estruturais, os dados podem ser usados para calibrar o modelo único simplificado e os modelos parciais que tenham como objetivo estudar as empenas do ponto de vista estrutural, geométrico e morfológico. 


\section{CONSIDERAÇÕES FINAIS}

A concepção de um modelo único para uso de todas as especialidades envolvidas na preservação do patrimônio edificado mostrou-se inviável, dado que cada qual necessita de conjunto de dados específicos para suas análises, os quais podem recorrer inclusive a diferentes delimitações geométricas (modelagens) das partes constituintes do edifício.

Portanto, propõe-se nesta pesquisa, como ponto de partida, a concepção de modelo do todo simplificado, a partir dos levantamentos georreferenciados (topográfico e laser scanning) além de medidas complementares tomadas in loco, que empregue ferramentas de "massas conceituais" (no caso do Autodesk Revit ${ }^{\circledR}$ ) com o objetivo de delimitar genericamente a geometria da edificação. Em seguida, cada especialidade se valeria dessas informações preliminares para concepção do modelo alterado com outras grandezas tomadas in loco e que melhor atenda aos seus objetivos. Evidentemente pode haver compartilhamento se objetivos forem similares ou convergentes.

Nesse contexto, a principal contribuição dos modelos digitais é a possibilidade de registro de dados levantados em campo, tais como os resultados dos ensaios destrutivos e não destrutivos realizados nas empenas e na cobertura do edifício, além do gerenciamento das mudanças no patrimônio edificado ao longo do tempo. A natureza dinâmica dessas mudanças - induzidas pela deterioração dos materiais, deslocamentos da estrutura, bem como das necessárias modificações de layout e ordenamento espacial do próprio edifício - requer um modelo confiável que possa ser um repositório de dados com informações rastreáveis e que possa ser alterado pelas diversas especialidades sem perda das suas referências fundamentais.

$\bigcirc$ modelo principal georreferenciado e os modelos derivados trazem melhorias incrementais às formas tradicionais de documentação do patrimônio edificado, geralmente baseadas em levantamentos fotográficos, narrativas escritas e desenhos planificados, ou mesmo tridimensionais, porém produzidos sem a lógica da parametrização.

Os modelos paramétricos tridimensionais também facilitam a visualização do edifício e suas partes pelos diversos agentes que intervêm na gestão do patrimônio, desde os profissionais das equipes de limpeza e manutenção preventiva até os especialistas que necessitam acessar os atributos dos vários sistemas do edifício para o diagnóstico e a proposição de intervenções para conservação. $\bigcirc$ referido processo de reconstrução digital está em andamento, e tem permitido ganhos incrementais no (re)conhecimento das características próprias do edifício Vilanova Artigas, notadamente da sua estrutura. $\bigcirc$ aprofundamento cognitivo requer a cuidadosa 
análise dos métodos de levantamento de dados, identificando suas potencialidades e limitações. Acima de tudo, a reconstrução digital do edifício deve servir ao propósito maior de viabilizar as intervenções de recuperação das suas condições de segurança e funcionalidade, com respeito ao seu valor histórico e cultural. 


\section{REFERÊNCIAS}

FONTES IMPRESSAS

ASSOCIAÇÃO BRASILEIRA DE NORMAS TÉCNICAS. ABNT NBR 7680-1: 2015. Concreto Extração, preparo, ensaio e análise de testemunhos de estruturas de concreto Parte 1: Resistência à compressão axial. Rio de Janeiro: ABNT, 2015.

FONTES ICONOGRÁFICAS

CONSERVAFAU. Edifício Vilanova Artigas. Perspectiva interna do salão Caramelo. 2016. 1. Fotografia.

CONSERVAFAU. Edifício Vilanova Artigas. Cobertura do edifício. 2015. 1. Fotografia.

CONSERVAFAU. Edifício Vilanova Artigas. Fachadas do edifício. 2016. 1. Modelo tridimensional obtido por varredura a laser.

CONSERVAFAU. Edifício Vilanova Artigas. Elevação de parte da fachada sudeste. 2016. 1. Imagem obtida a partir da nuvem de pontos do modelo tridimensional.

CONSERVAFAU. Edifício Vilanova Artigas. Elevação completa da fachada sudeste. 2016. 1. Imagem obtida a partir do modelo tridimensional da varredura a laser.

CONSERVAFAU. Edifício Vilanova Artigas. Elevação do trecho da fachada. 2016. 1. Imagem obtida a partir do modelo tridimensional da varredura a laser. 2. Fotografia

LIVROS, ARTIGOS E TESES

BALZANI, Marcello; MAIETTI, Frederica; MUGAYAR KÜHL, Beatriz. Point cloud analysis for conservation and enhancement of modernist architecture. International Archives of the Photogrammetry, Remote Sensing and Spatial Information Sciences, v. XLII-2/W3, p. 71-77, 2017. 
CANUTO, Cristiane Lopes; SALGADO, Mônica Santos. Modelagem da informação da construção na preservação da arquitetura moderna. XVI Encontro Nacional de Tecnologia do Ambiente Construído. Desafios e Perspectivas da Internacionalização da Construção. São Paulo, 2016. Disponível em: <https://bit.ly/2WKzpdK>. Acesso em: 11 dez. 2018.

CASTRO, Carmen. S. S. M. de. Para além das aparências: contribuição ao estudo da conservação da superfície arquitetônica de concreto aparente. 2018, 281 f. Dissertação (Mestrado). Faculdade de Arquitetura e Urbanismo, Universidade de São Paulo, São Paulo.

GALLO JUNIOR, Fabio et al. Emprego de ultrassom na documentação do patrimônio moderno: o concreto do edifício Vilanova Artigas. In: II Simpósio Científico anual do ICOMOS Brasil, 2018, Belo Horizonte. Anais do II Simpósio Científico 2018. Belo Horizonte: Universidade Federal de Minas Gerais - UFMG, 2018. v. I. p. 1196-1229. Disponível em: <https://bit.ly/3fI6vDz>. Acesso em: 5 jan. 2019

OLIVEIRA, Mario Mendonça de. A documentação como ferramenta de preservação da memória. Brasília, DF: IPHAN; Programa Monumenta, 2008. 144 p. (Cadernos Técnicos 7).

PINHEIRO, Maria Lucia Bressan et al. Subsidies for a conservation management plan: Vilanova Artigas Building (School of Architecture and Urbanism of the University of São Paulo). Technical Report. Keeping It Modern. The Getty Foundation. 2017. Disponível em: <https://bit.ly/2Afh00X>. Acesso em: 18 nov. 2019.

TOLENTINO, Mônica Martins Andrade. A utilização do HBIM na documentação, na gestão e na preservação do Patrimônio Arquitetônico. XX Congress of the Iberoamerican Society of Digital Graphics. Buenos Aires, 2016. Disponível em: <https://go.aws/3fGYqz7>. Acesso em: 11 dez. 2018.

Artigo apresentado em 21/03/2019. Aprovado em 25/03/2020. (c) BY 